\title{
Inhibition of quorum sensing in Pseudomonas aeruginosa by azithromycin and its effectiveness in urinary tract infections
}

Correspondence

Kusum Harjai

kusum_harjai@hotmail.com

Received 22 August 2010

Accepted 1 December 2010

\author{
Anju Bala, Ravi Kumar and Kusum Harjai \\ Department of Microbiology, BMS Block, Panjab University, Chandigarh 160014, India
}

\section{INTRODUCTION}

Quorum sensing (QS) is an important global gene regulatory mechanism in bacteria that enables individual bacteria to coordinate their behaviour in populations. The QS system relies on self-generated signalling molecules, which coordinate gene expression in response to population density (Rumbaugh et al., 2000). Many processes that assist in the survival, persistence and pathogenesis of Pseudomonas aeruginosa, such as the expression of virulence factors and biofilm formation, are under the control of QS. Two interrelated QS systems, las and $r h l$, have been reported in $P$. aeruginosa and act in a hierarchical manner (Davies et al., 1998; Favre-Bonté et al., 2003; de Kievit, 2009). Both systems consist of inducer and regulatory proteins and a cognate autoinducer signal molecule, $\mathrm{N}$-(3-oxododecanoyl) homoserine lactone (OdDHL) and $\mathrm{N}$-butanoyl homoserine lactone (BHL), respectively (Rumbaugh et al., 2000; Venturi, 2006).

$P$. aeruginosa causes infections in a variety of situations, such as cystic fibrosis, burns, cancer and traumatic wounds, especially in immunocompromised hosts, and can be a problem in intensive care units (Van Delden \& Iglewski, 1998; Singh et al., 2000; Ehrlich et al., 2002). It has a tendency to form biofilms on biotic and abiotic surfaces such as catheters and lead to persistent and chronic urinary

Abbreviations: AZM, azithromycin; $\mathrm{BHL}, \mathrm{N}$-butanoyl homoserine lactone; $\mathrm{MU}$, Miller unit; OdDHL, $\mathrm{N}$-(3-oxododecanoyl) homoserine lactone; p.i., post-infection; OS, quorum sensing; UTI, urinary tract infection. tract infections (UTIs) (Donlan \& Costerton, 2002; Willcox et al., 2008). These biofilms are usually resistant to antibiotics and host immune defence clearance, and hence are difficult to eradicate by antibiotic intervention (Ceri et al., 1999; Costerton et al., 1999; Donlan, 2001).

Although antibiotic therapy has great benefits in treatment, the emergence of multidrug resistance in $P$. aeruginosa has left clinicians with limited therapeutic options. Azithromycin (AZM), a member of the macrolide class of antibiotics, is used to cure certain bacterial infections, primarily caused by Grampositive bacteria but also some Gram-negative pathogens. However, many clinical and experimental studies have shown beneficial effects of AZM in the treatment of patients with diffuse panbronchiolitis and cystic fibrosis, which are associated with $P$. aeruginosa infection (Pechère, 2001; Tateda et al., 2001). Looking at the multiple actions of macrolides, such as their anti-inflammatory effect (Tsai et al., 2004; Amsden, 2005) and inhibition of the synthesis of alginate (Skindersoe et al., 2008), the present study aimed to evaluate the role of AZM in QS, swimming, swarming and twitching motilities, and biofilm formation of $P$. aeruginosa. Further therapeutic potential of AZM in a mouse model of UTI caused by $P$. aeruginosa was also analysed.

\section{METHODS}

Bacterial strains. Twenty-five clinical isolates of $P$. aeruginosa isolated from urine samples of patients having catheter-associated 
UTI attending the Government Medical College and Hospital, Chandigarh, India, along with the $P$. aeruginosa standard strain PAO1 were used in this study. The study protocol was approved by the Panjab University Ethical Committee. Two reporter strains, Escherichia coli MG4(21.4) and PAO-JP2(pECP61.5), were also used. These reporter strains were grown under antibiotic pressure from ampicillin $\left(100 \mu \mathrm{g} \mathrm{ml}^{-1}\right)$ and carbenicillin $\left(250 \mu \mathrm{g} \mathrm{ml}^{-1}\right)$ for the detection of OdDHL and BHL, respectively. All strains were maintained as $10 \%$ glycerol stocks and stored at $-80{ }^{\circ} \mathrm{C}$. Fresh subcultures were prepared for each new experiment from glycerol stocks.

MIC determination. The MIC of AZM (HiMedia Laboratories) was determined according to NCCLS (2002) guidelines against the standard $P$. aeruginosa strain PAOl and clinical strains PA1 and PA2. Briefly, from stock solutions of AZM $\left(10 \mathrm{mg} \mathrm{ml}^{-1}\right)$, different dilutions of $5-200 \mu \mathrm{g} \mathrm{ml}^{-1}$ were prepared. A $6 \mathrm{~h}$ culture was used as the inoculum. The concentration of antibiotic resulting in no visible growth was taken as the MIC. For all further experiments, a sub-MIC of AZM was used for all three strains.

Estimation of QS signals ( $\mathrm{N}$-acyl homoserine lactones). Supernatant was extracted from overnight cultures grown in the presence or absence of AZM and $\beta$-galactosidase activity was determined. The reporter culture was diluted $1: 1$ in $\mathrm{Z}$ buffer $\left(\mathrm{Na}_{2} \mathrm{HPO}_{4} \cdot 7 \mathrm{H}_{2} \mathrm{O} \quad 0.06 \mathrm{M}, \mathrm{NaH}_{2} \mathrm{PO}_{4} \cdot \mathrm{H}_{2} \mathrm{O} \quad 0.04 \mathrm{M}, \mathrm{KCl} 0.01 \mathrm{M}\right.$, $\mathrm{MgSO}_{4} .7 \mathrm{H}_{2} \mathrm{O} 0.001 \mathrm{M}, \beta$-ME $0.05 \mathrm{M}, \mathrm{pH} 7.0$ ) and assayed for $\beta$ galactosidase activity by using ONPG as substrate, as described by Miller (1972).

Motility assays. Swimming, swarming and twitching motilities were assayed on agar plates containing specialized medium with or without a sub-MIC of AZM (Rashid \& Kornberg, 2000). For the motility assays, organisms were grown overnight in the absence of AZM and then inoculated onto motility plates with AZM.

Swimming. Plates containing $1 \%$ tryptone, $0.5 \% \mathrm{NaCl}$ and $0.3 \%(\mathrm{w} / \mathrm{v})$ Bacto agar were prepared for the assay. Swimming plates were pointinoculated from an overnight culture with a sterile toothpick and incubated at $30{ }^{\circ} \mathrm{C}$ for $24 \mathrm{~h}$. The zone diameter was measured to assess swimming motility.

Swarming. Nutrient broth $\left(8 \mathrm{~g} \mathrm{l}^{-1}\right)$ supplemented with $5 \mathrm{~g}$ glucose $1^{-1}$ was prepared. The medium was solidified by the addition of $0.5 \%$ $(\mathrm{w} / \mathrm{v})$ Bacto agar. The plates were point-inoculated from an overnight culture with a sterile toothpick and incubated at $37^{\circ} \mathrm{C}$ for $24 \mathrm{~h}$. Swarming motility was assessed by measuring the circular turbid zones formed by the bacterial cells migrating away from the point of inoculation.

Twitching. Freshly prepared Luria-Bertani agar plates (1\% Bacto agar) were used for the assay. Overnight cultures were stabbed with a sterile toothpick through the agar layer to the bottom of the Petri dish. The plates were then incubated at $37^{\circ} \mathrm{C}$ for $48 \mathrm{~h}$. The ability of bacteria to adhere on the polystyrene surface was examined by removing the agar and staining the attached cells with crystal violet $(0.1 \%, \mathrm{w} / \mathrm{v})$. The plates were washed gently with tap water to remove any unattached cells before staining. The diameter of the stained zone was measured to assess the twitching motility.

Biofilm-forming capacity. Biofilm-forming capacity was determined by a microtitre plate assay, as described by Wagner et al. (2007). Biofilms were allowed to develop in microtitre plates with and without AZM. The plate was incubated at $37{ }^{\circ} \mathrm{C}$ for $24 \mathrm{~h}$ under static conditions. After $24 \mathrm{~h}$, the wells were drained and washed three times with sterile PBS to remove free cells. The wells were stained with crystal violet $(0.1 \%, \mathrm{w} / \mathrm{v})$ for $15 \mathrm{~min}$ at room temperature. Excess dye was removed by washing the wells with sterile PBS. Dye taken up by the biofilm cells was extracted with $95 \%$ (v/v) ethanol. Absorbance was measured at $570 \mathrm{~nm}$ and biofilm-forming capacity was calculated as $A_{570}$ of the strain in the presence of $\mathrm{AZM} / A_{570}$ of the strain in the absence of AZM. A control without antibiotic was run simultaneously.

Biofilm generation. Sterile Foley catheter pieces (Rusch) of $1 \mathrm{~cm}$ were cut and a biofilm was allowed to develop under static conditions for 7 days as described previously in the presence or absence of a subMIC of AZM (Mittal et al., 2006). The catheter pieces were transferred to fresh medium every $24 \mathrm{~h}$. Each day, the catheter pieces in duplicate were removed, rinsed three times with PBS and cells were removed from the surface by scraping the surface with a sterile scalpel blade. The cells were sonicated using a low-level sonication cycle and vortexed for $30 \mathrm{~s}$. Dispersed samples were then centrifuged and the biofilm cells were suspended in $1 \mathrm{ml}$ PBS. Serial dilutions were prepared and plated on MacConkey agar plates.

\section{Therapeutic effect of AZM in vivo}

Establishment of experimental UTI. The method of Harjai et al. (2005) was used for induction of a UTI. Ethical approval for the use of animals was granted by the Panjab University Ethical Committee. Female LACA (Swiss Webster) mice, 6-8 weeks old and free of bacteraemia, were used for the experiment. Four groups consisting of eight animals each were used. Control group 1 was infected without any further treatment. In control group 2, $1 \mathrm{ml}$ sterile normal saline was given orally and intravenously to infected animals. In groups 3 and 4 , infected animals were treated orally $(400 \mu \mathrm{l})$ or intravenously $(100 \mu \mathrm{l})$ with AZM [500 $\mathrm{mg}(\mathrm{kg} \text { body } \mathrm{wt})^{-1}$ ] from the day of infection to the day of sacrifice. On day $0,50 \mu$ adjusted inoculum $\left(10^{8}\right.$ c.f.u. $\mathrm{ml}^{-1}$ ) was introduced into the bladder of the mice using a soft intramediac, non-radio-opaque polyethylene tubing (outer diameter $0.61 \mathrm{~mm}$; Clay Adams).

Bacteriological examination. Animals were sacrificed on days 3 and 5 post-infection (p.i.). Aseptically removed kidneys were weighed and homogenized in $1 \mathrm{ml}$ sterile saline. Quantitative bacterial counts (c.f.u.) were calculated (g kidney tissue) ${ }^{-1}$, as reported by Kakar et al. (1986).

Histopathological examination. Kidney tissue from infected animals from all groups of mice was fixed in $10 \%$ normal buffered saline and dehydrated in $30-100 \%$ ethanol. Paraffin wax blocks were prepared and $5 \mu \mathrm{m}$ thin sections were stained with haematoxylin and eosin. The medulla, cortex, calyx and subcalyx of each kidney were evaluated for histopathological changes with the help of an expert pathologist.

Statistical analysis. All experiments were carried out in triplicate to validate the reproducibility of the experiments. The results were analysed statistically using Student's $t$-test with GraphPad Prism software to calculate $P$ values. $P<0.05$ was taken as statistically significant.

\section{RESULTS AND DISCUSSION}

\section{Effect of AZM on QS signals}

The pathogenicity of $P$. aeruginosa is controlled by QS signals (Van Delden \& Iglewski, 1998). Therefore, in the present study, the effect of AZM on production of the QS signal molecules OdDHL and BHL was evaluated. Two clinical isolates, PA1 and PA2, producing comparable levels of QS signal molecules compared with the standard strain $\mathrm{PAO} 1$ and having the maximum biofilm-forming capacity 
of all the isolates, were used for further study, along with strain PAO1. The MIC for AZM for P. aeruginosa PAO1 was determined as $177 \mu \mathrm{g} \mathrm{ml}^{-1}$. A sub-MIC $(88.5 \mu \mathrm{g}$ $\mathrm{ml}^{-1}$ ) was used for all further experiments. Strain PAO1 produced 818 Miller units (MU) BHL and $137 \mathrm{MU}$ OdDHL in absence of AZM (Fig. 1). The levels of BHL and OdDHL decreased to $372 \mathrm{MU}(P<0.001)$ and $120 \mathrm{MU}$ $(P<0.01)$, respectively, in the presence of AZM. The clinical isolates PA1 and PA2 also showed a reduction in the production of $\mathrm{BHL}$ and OdDHL in the presence of AZM (Fig. 1), indicating that macrolides interfere with the production of QS signals in $P$. aeruginosa. It has been observed by other workers that a sub-MIC of erythromycin, another macrolide, also reduces the production of QS signal molecules (Sofer et al., 1999). AZM is neither bactericidal nor bacteriostatic in $P$. aeruginosa, but it inhibits QS signal production and may lead to attenuation of the virulence of $P$. aeruginosa. This approach could prove beneficial when exploited in different $P$. aeruginosainduced infections in various animal models.

\section{Effect of AZM on motility}

$P$. aeruginosa exhibits three types of motility - swimming, swarming and twitching - which are mediated by flagella and type IV pili (Köhler et al., 2000; Rashid \& Kornberg, 2000). Whilst flagellum-mediated motility has been implicated in bringing $P$. aeruginosa within proximity of the surface, type IV pili enable the organism to migrate across biotic surfaces, recruit cells from adjacent monolayers and form cell aggregates (O'Toole et al., 1999). To see the effect of AZM on the swimming, swarming and twitching motilities of $P$. aeruginosa, strains PAO1, PA1 and PA2 were grown overnight in the absence of AZM and then inoculated onto motility plates with AZM. It was observed that the presence of AZM significantly reduced all three types of motility (Table 1, Fig. 2). Molinari et al. (1992) also observed a reduction in motility of $P$. aeruginosa on exposure to a sub-MIC of AZM, hence confirming the ability of AZM to reduce the expression of virulence factors. Nalca et al. (2006) also demonstrated an inhibitory effect of AZM on swimming and twitching motilities, with delayed and impaired alginate production.

\section{Effect of AZM on biofilm formation}

The biofilm-forming capacity of strains PAO1, PA1 and PA2 was calculated in the presence and absence of AZM. The results demonstrated that AZM significantly reduced biofilm-forming capacity in all three strains $(P<0.001$; Fig. 3 ). The effect of AZM was also determined on different stages of biofilm formation by quantifying $\log$ (c.f.u. $\mathrm{ml}^{-1}$ ) values. Biofilm was generated on Foley catheters for 7 successive days in the absence or presence of AZM. In the absence of AZM, strain PAO1 showed an increase in the $\log$ count of biofilm formation from day 1 with a maximum peak value $(11.0 \pm 0.32)$ on day 4 , after which a decline was observed up to day 7 (Fig. 4). The peak on day 4 was indicative of maximum accumulation of bacterial cells on the surface of the catheter. In the presence of AZM, a significant reduction in the log c.f.u. of biofilms was observed $(5.6 \pm 0.08)$ for PAO1 on the peak day of biofilm formation, i.e. day 4. The clinical isolates PA1 and PA2 also showed a similar trend with a reduction in the peak on day 4 and a significant reduction in biofilm formation over 7 days in the presence of AZM (Fig. 4). The reduction in $\log$ count was indicative of thinner and reduced biofilm formation. These kinds of biofilms show increased permeability and penetration of antibiotics through the extracellular polymeric substance (Mikuniya et al., 2005). Ichimiya et al. (1996) have also shown that AZM can inhibit biofilm formation significantly by inhibiting the production of alginic acid by mucoid strains and the production of exopolysaccharides by non-mucoid strains of $P$. aeruginosa. Impairment of the ability of $P$. aeruginosa to form fully polymerized alginate biofilms may help in attenuating the virulence of $P$. aeruginosa (Hoffmann et al., 2007).

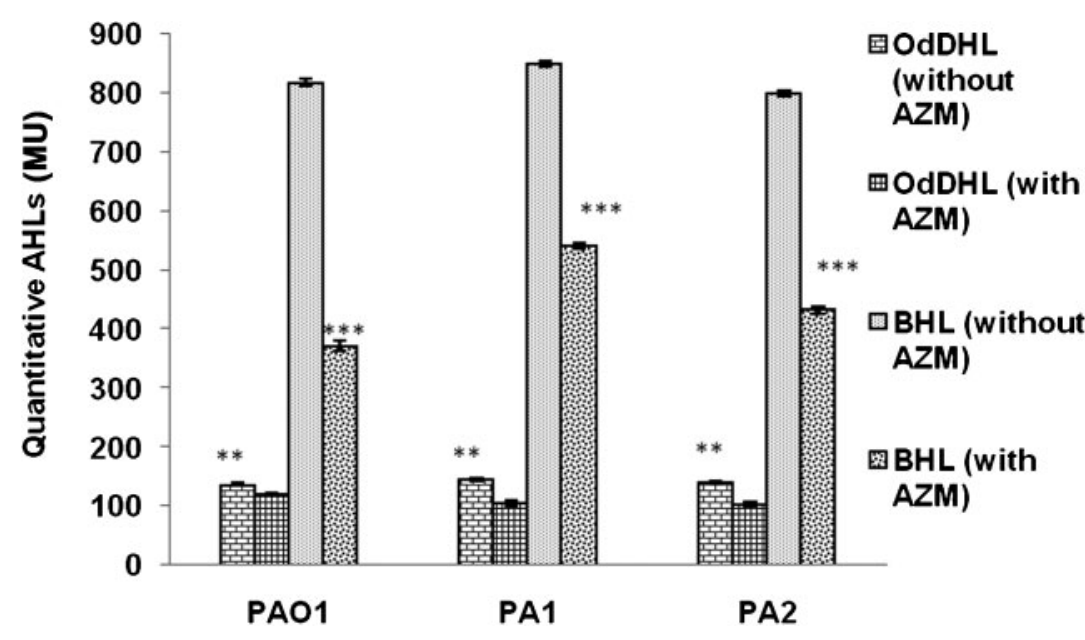

Fig. 1. Production of the OS signal molecules $\mathrm{BHL}$ and OdDHL as estimated by a $\beta$ galactosidase assay in culture supernatants of standard strain PAO1 and clinical isolates PA1 and PA2 in the absence or presence of a sub-MIC of AZM. The results are presented as means $\pm S D$ obtained from three independent experiments. ${ }^{\star *}, P<0.01 ;{ }^{* \star}, P<0.001$. 
Table 1. Comparison of the swimming, swarming and twitching motilities shown by standard strain PAO1 and clinical isolates PA1 and PA2 in the absence or presence of a sub-MIC of AZM

Results are given as zone diameters $(\mathrm{cm})$.

\begin{tabular}{|lcccc|}
\hline Motility & AZM & PAO1 & PA1 & PA2 \\
\hline Swimming & + & $0.73 \pm 0.058$ & $0.53 \pm 0.058$ & $0.73 \pm 0.06$ \\
& - & $0.1 \pm 0.01^{* *}$ & $0.1 \pm 0.01^{* *}$ & $0.27 \pm 0.056^{* *}$ \\
Swarming & + & $0.53 \pm 0.057$ & $1.7 \pm 0.012$ & $1.03 \pm 0.058$ \\
Twitching & - & $0.12 \pm 0.029^{*}$ & $0.4 \pm 0.01^{* * *}$ & $0.4 \pm 0.029^{* *}$ \\
& + & $0.23 \pm 0.058$ & $1.15 \pm 0.05$ & $0.45 \pm 0.05$ \\
& - & $0.1 \pm 0.01$ & $0.2 \pm 0.029^{* * *}$ & $0.2 \pm 0.06$ \\
\end{tabular}

${ }^{\star}, P<0.05$ (significant); ${ }^{* *}, P<0.01$ (very significant); ${ }^{* *}, P<0.001$ (extremely significant).

\section{Potential efficacy of AZM in treatment of experimental UTIs}

A significant reduction in QS signal molecules and a reduction in the formation of biofilm by $P$. aeruginosa was observed in vitro. The therapeutic potential of AZM in a mouse model of ascending UTI, where the motility of the organism provides an additional benefit in ascending to the renal tissue, was then evaluated. Standard strain PAO1 was used to infect the animals. Animals in all groups were sacrificed on day 3 or 5 p.i. On day 3 p.i., control group animals (untreated and saline-treated mice) showed

(a)

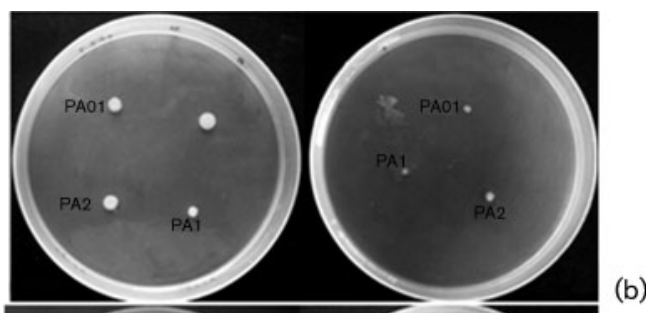

(c)

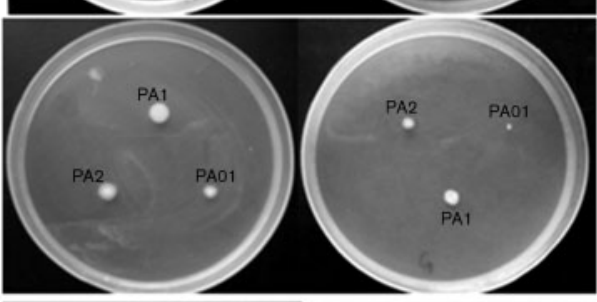

(b)

(d)

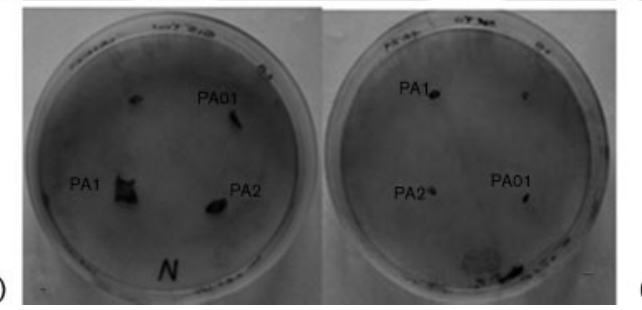

(f)

Fig. 2. Demonstration of the swimming ( $a, b)$, swarming (c, d) and twitching $(e, f)$ motilities of standard strain PAO1 and clinical isolates PA1 and PA2 in the absence (controls: a, c, e) and presence (test plates: $b, d, f$ ) of AZM. comparable renal bacterial counts of $5.75 \pm 0.11$ and $5.38 \pm 0.06\left[\log\right.$ (c.f.u. $\mathrm{g}^{-1}$ )], respectively. A significant reduction in $\log$ count of $3.18 \pm 0.11$ and $3.36 \pm 0.31$ was observed in the groups of mice treated intravenously and orally with AZM, respectively, on day 3 p.i. $(P<0.05)$. On day 5 p.i., untreated and saline-treated mice showed renal bacterial counts of $3.67 \pm 0.07$ and $3.50 \pm 0.05$, whereas no bacteria could be recovered from the renal tissue of mice on day 5 p.i. from the treatment groups (Fig. 5), indicating clearance of infection by day 5 p.i. following AZM treatment. Inhibition of the production of QS signal molecules and the inability to form a thick and mature biofilm in the presence of AZM could have led to complete clearance of the organisms from the kidney tissue of infected mice.

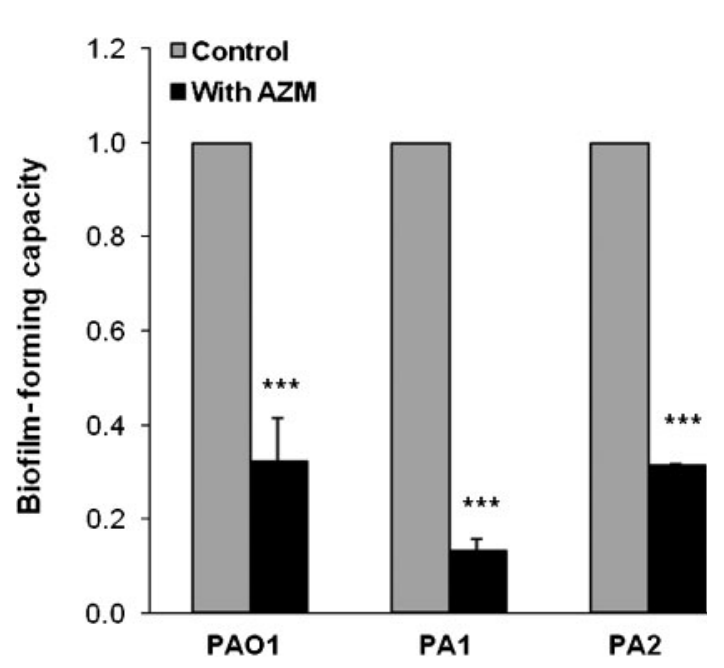

Fig. 3. Demonstration of biofilm-forming capacity estimated by a crystal violet assay of $P$. aeruginosa standard strain PAO1 and clinical isolates PA1 and PA2 in the absence or presence of a sub-MIC of AZM. A standard reference value of 1 was taken as the control (no AZM) for each strain. The results are presented as means $\pm S D$ obtained from three independent experiments. $\star * \star, P<0.001$. 


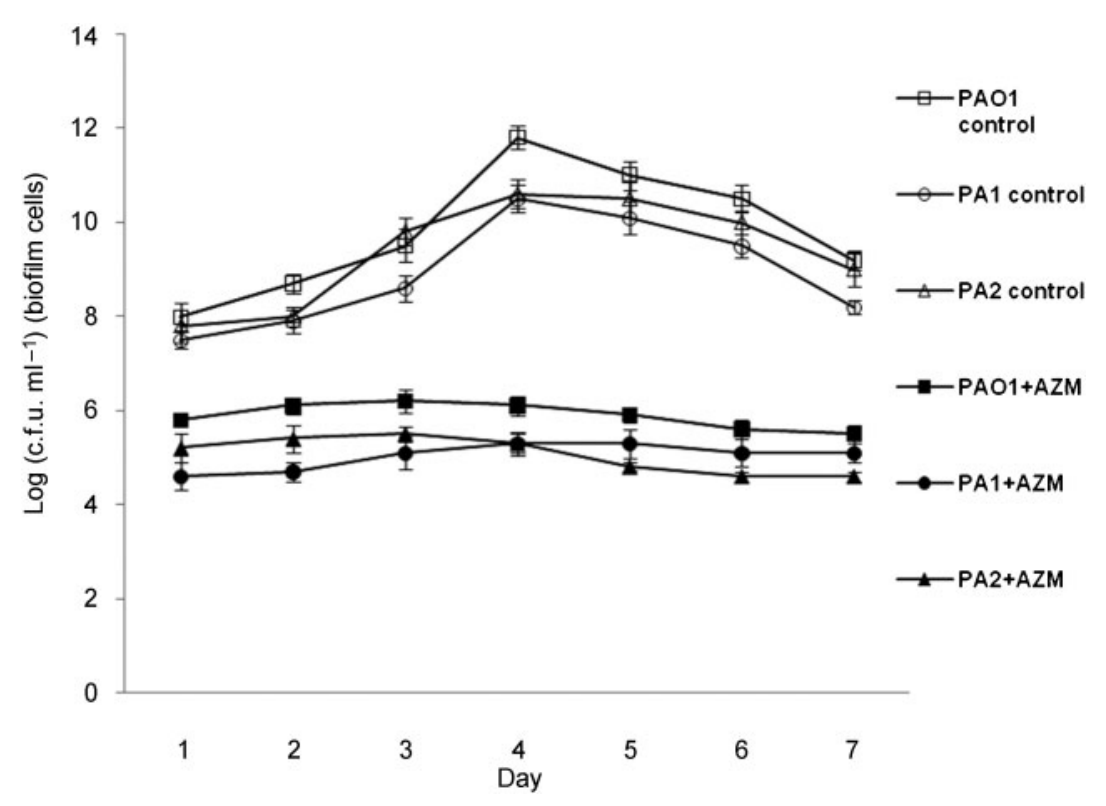

Fig. 4. Generation of biofilms on Foley catheters as $\log$ (c.f.u. $\mathrm{ml}^{-1}$ ) of $P$. aeruginosa standard strain PAO1 and clinical isolates PA1 and PA2 from day 1 to day 7 in the absence or presence of a sub-MIC of AZM. The results are presented as means $\pm S D$ obtained from three independent experiments.
On histopathological examination, the renal tissue of untreated but infected mice and saline-treated mice showed severe inflammation with infiltration of polymorphonuclear leukocytes and plasma cells in the glomeruli and subepithelium of the renal pelvis (Fig. 6). In contrast, infected mice treated with AZM showed mild inflammation with normal glomeruli and tubules in the medulla and cortex regions of the renal tissue. The renal tissue of uninfected mice without treatment or treated with AZM did not show any histopathological changes, suggesting no effect of AZM on renal tissue. The histopathological results were in accordance with the bacteriological findings, showing significant differences between the test and control groups. In the treated group, renal tissue destruction was reduced in comparison with the control groups. The role of $\mathrm{N}$-acyl homoserine lactones in tissue inflammation has been observed previously by a number of workers (Rumbaugh et al., 1999; Smith et al., 2002; Kumar et al., 2009). Reduced tissue inflammation in the treatment groups indicated that AZM, besides inhibiting QS, also plays an anti-inflammatory role during UTIs and hence protects tissue from inflammation. The ability of AZM to reduce tissue inflammation further confirmed the effectiveness of AZM for treatment of experimental UTIs.

Although AZM has been shown to exert a therapeutic effect in cystic fibrosis and diffuse panbronchiolitis in mouse lung infection models (Wolter \& McCormack, 1998; Saiman et al., 2002; Hansen et al., 2005), to the best of our knowledge, the present report is the first to show the potential efficacy of AZM in the treatment of UTIs caused by $P$. aeruginosa in a mouse model. Increased clearance of $P$. aeruginosa biofilms, reduced lung pathology and favourable modulation of the immune response in the lung infection model has also been observed by a number of workers (Nicolau et al., 1999; Moser et al., 2002; Hoffmann et al., 2007). In the present study, treatment with AZM improved the outcome of UTIs caused by $P$.

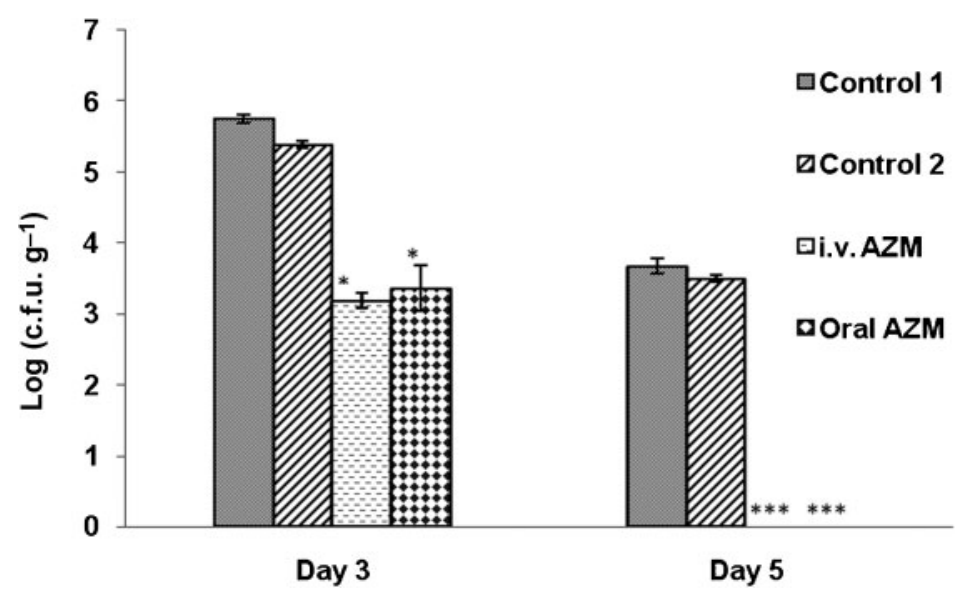

Fig. 5. Renal bacterial load (c.f.u. $\mathrm{g}^{-1}$ ) of infected and treated mice sacrificed on days 3 and day 5 p.i. after intrauretheral challenge with $P$. aeruginosa strain PAO1. Mice groups were given oral or intravenous (i.v.) treatment with AZM. Control group 1 comprised infected mice without treatment and control group 2 comprised infected mice with saline treatment. ${ }^{*}, P<0.05 ;{ }^{* \star *}, P<0.001$. 
(a)

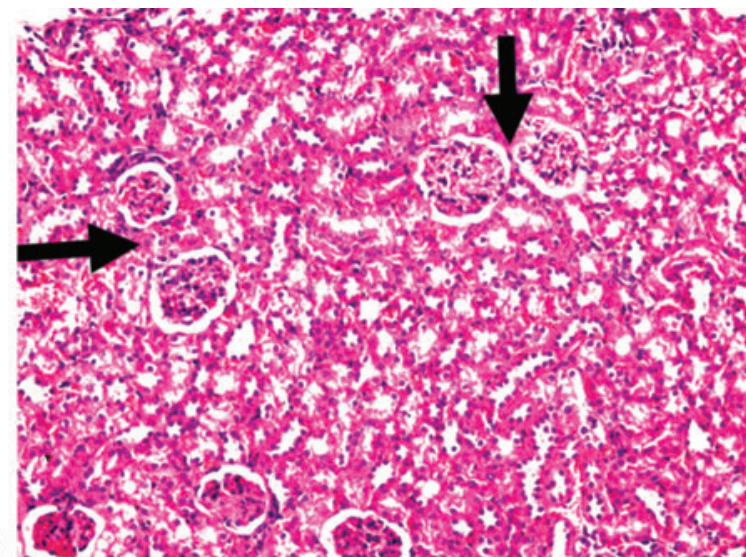

(b)

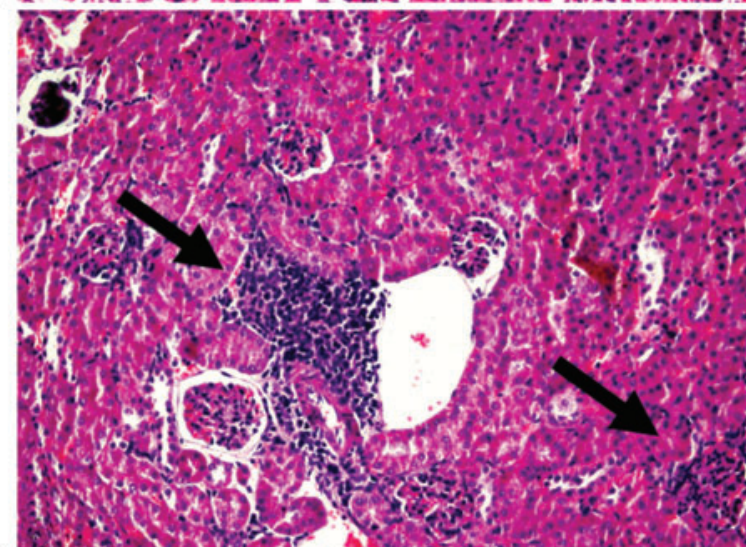

(c)

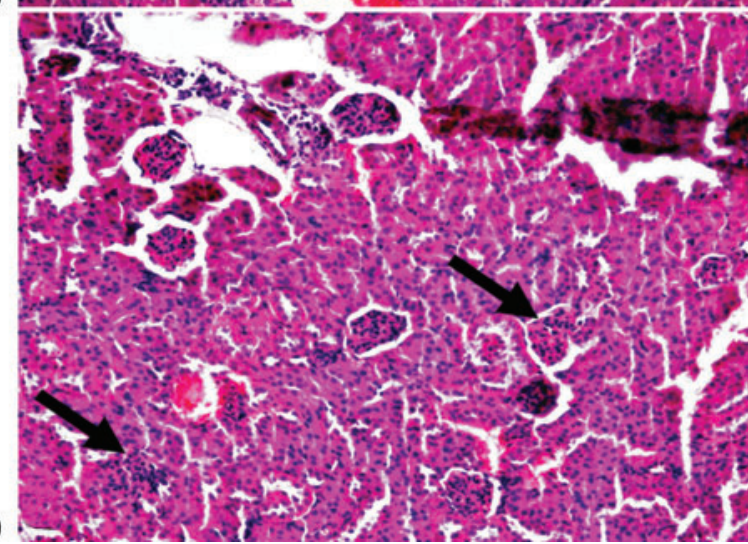

Fig. 6. (a) Photomicrograph of renal tissue of normal uninfected mice. Normal glomeruli are indicated by arrows. (b) Infiltration of polymorphonuclear leukocytes along with plasma cells in the interstitium and severe inflammation in tubules in the medulla region in the kidney tissue of control untreated mice infected with $P$. aeruginosa. (c) Normal to mild inflammation with reduced infiltration of polymorphonuclear leukocytes in the interstitium, with normal tubules of the medulla region in kidney tissue of infected and AZM-treated mice. Sections were stained with haematoxylin and eosin. Original magnification, $\times 100$. The arrows in (b) and (c) indicate histopathological changes.

aeruginosa in a mouse model. It was concluded that AZM can be used as a QS inhibitor or antagonist to potentially reduce the virulence of $P$. aeruginosa. The use of AZM could also be explored further as an adjunctive therapy with other antibiotics for the treatment of UTIs caused by $P$. aeruginosa. More studies on the use of AZM in a UTI model in the context of modulation of the immune response will throw more light on the therapeutic potential of AZM in kidney infection of mice.

\section{ACKNOWLEDGEMENTS}

The authors gratefully acknowledge Dr Barbara H. Iglewski for providing the reporter strains and the standard strain PAO1.

\section{REFERENCES}

Amsden, G. W. (2005). Anti-inflammatory effects of macrolides - an underappreciated benefit in the treatment of community-acquired respiratory tract infections and chronic inflammatory pulmonary conditions? J Antimicrob Chemother 55, 10-21.

Ceri, H., Olson, M. E., Stremick, C., Read, R. R., Morck, D. \& Buret, A. (1999). The Calgary Biofilm Device: new technology for rapid determination of antibiotic susceptibilities of bacterial biofilms. J Clin Microbiol 37, 1771-1776.

Costerton, J. W., Stewart, P. S. \& Greenberg, E. P. (1999). Bacterial biofilms: a common cause of persistent infections. Science 284, 13181322.

Davies, D. G., Parsek, M. R., Pearson, J. P., Iglewski, B. H., Costerton, J. W. \& Greenberg, E. P. (1998). The involvement of cell-to-cell signals in the development of a bacterial biofilm. Science 280, 295298.

de Kievit, T. R. (2009). Quorum sensing in Pseudomonas aeruginosa biofilms. Environ Microbiol 11, 279-288.

Donlan, R. M. (2001). Biofilms and device-associated infections. Emerg Infect Dis 7, 277-281.

Donlan, R. M. \& Costerton, J. W. (2002). Biofilms: survival mechanisms of clinically relevant microorganisms. Clin Microbiol Rev 15, 167-193.

Ehrlich, G. D., Veeh, R., Wang, X., Costerton, J. W., Hayes, J. D., Hu, F. Z., Daigle, B. J., Ehrlich, M. D. \& Post, J. C. (2002). Mucosal biofilm formation on middle-ear mucosa in the chinchilla model of otitis media. JAMA 287, 1710-1715.

Favre-Bonté, S., Köhler, T. \& Van Delden, C. (2003). Biofilm formation by Pseudomonas aeruginosa: role of the C4-HSL cell-to-cell signal and inhibition by azithromycin. J Antimicrob Chemother 52, 598-604.

Hansen, C. R., Pressler, T., Koch, C. \& Høiby, N. (2005). Long-term azithromycin treatment of cystic fibrosis patients with chronic $P$. aeruginosa infection; an observational cohort study. J Cyst Fibros 4, 35-40.

Harjai, K., Khandwahaa, R. K., Mittal, R., Yadav, V., Gupta, V. \& Sharma, S. (2005). Effect of $\mathrm{pH}$ on production of virulence factors by biofilm cells of P. aeruginosa. Folia Microbiol (Praha) 50, 99-102.

Hoffmann, N., Lee, B., Hentzer, M., Rasmussen, T. B., Song, Z., Johansen, H. K., Givskov, M. \& Høiby, N. (2007). Azithromycin blocks quorum sensing and alginate polymer formation and increases the sensitivity to serum and stationary-growth-phase killing of Pseudomonas aeruginosa and attenuates chronic P. aeruginosa lung infection in $\mathrm{Cftr}^{-1-}$ mice. Antimicrob Agents Chemother 51, 36773687. 
Ichimiya, T., Takeoka, K., Hiramatsu, K., Hirai, K., Yamasaki, T. \& Nasu, M. (1996). The influence of azithromycin on the biofilm formation of Pseudomonas aeruginosa in vitro. Chemotherapy 42, 186-191.

Kakar, K., Sharma, S., Asnani, P. J., Banerjee, C. K. \& Sharma, B. K. (1986). Experimental haematogenous pyelonephritis in mice with uropathogenic, enteropathogenic and enterotoxigenic Escherichia coli. Antonie van Leeuwenhoek 52, 153-161.

Köhler, T., Curty, L. K., Barja, F., van Delden, C. \& Pechère, J.-C. (2000). Swarming of Pseudomonas aeruginosa is dependent on cell-tocell signaling and requires flagella and pili. J Bacteriol 182, 5990-5996.

Kumar, R., Chhibber, S. \& Harjai, K. (2009). Quorum sensing is necessary for the virulence of Pseudomonas aeruginosa during urinary tract infection. Kidney Int 76, 286-292.

Mikuniya, T., Kato, Y., Kariyama, R., Monden, K., Hikida, M. \& Kumon, H. (2005). Synergistic effect of fosfomycin and fluoroquinolones against Pseudomonas aeruginosa growing in a biofilm. Acta Med Okayama 59, 209-216.

Miller, J. H. (1972). Experiments in Molecular Genetics. Cold Spring Harbor, NY: Cold Spring Harbor Laboratory.

Mittal, R., Chhibber, S., Sharma, S. \& Harjai, K. (2006). Effect of macrophage secretory products on elaboration of virulence factors by planktonic and biofilm cells of Pseudomonas aeruginosa. Comp Immunol Microbiol Infect Dis 29, 12-26.

Molinari, G., Paglia, P. \& Schito, G. C. (1992). Inhibition of motility of Pseudomonas aeruginosa and Proteus mirabilis by subinhibitory concentrations of azithromycin. Eur J Clin Microbiol Infect Dis 11, 469-471.

Moser, C., Jensen, P. O., Kobayashi, O., Shirai, R., Hougen, H. P. \& Hoiby, N. (2002). Macrolide treatment improves outcome and reduces IL-4 production in susceptible Balb/C mice with chronic Pseudomonas aeruginosa lung infection. Pediatr Pulmonol Suppl 24, 275-280.

Nalca, Y., Jänsch, L., Bredenbruch, F., Geffers, R., Buer, J. \& Häussler, S. (2006). Quorum-sensing antagonistic activities of azithromycin in Pseudomonas aeruginosa PAO1: a global approach. Antimicrob Agents Chemother 50, 1680-1688.

NCCLS (2002). Performance Standards for Antimicrobial Susceptibility Testing, 12th Informational Supplement. M100-S12. Wayne, PA: National Committee for Clinical Laboratory Standards.

Nicolau, D. P., Banevicius, M. A., Nightingale, C. H. \& Quintiliani, R. (1999). Beneficial effect of adjunctive azithromycin in treatment of mucoid Pseudomonas aeruginosa pneumonia in the murine model. Antimicrob Agents Chemother 43, 3033-3035.

O'Toole, G. A., Pratt, L. A., Watnick, P. I., Newman, D. K., Weaver, V. B. \& Kolter, R. (1999). Genetic approaches to the study of biofilms. Methods Enzymol 310, 91-109.

Pechère, J. C. (2001). Azithromycin reduces the production of virulence factors in Pseudomonas aeruginosa by inhibiting quorum sensing. Jpn J Antibiot 54, 87-89.

Rashid, M. H. \& Kornberg, A. (2000). Inorganic polyphosphate is needed for swimming, swarming, and twitching motilities of Pseudomonas aeruginosa. Proc Natl Acad Sci U S A 97, 4885-4890.
Rumbaugh, K. P., Griswold, J. A., Iglewski, B. H. \& Hamood, A. N. (1999). Contribution of quorum sensing to the virulence of $P$. aeruginosa in burn wound infections. Infect Immun 67, 5854-5862.

Rumbaugh, K. P., Griswold, J. A. \& Hamood, A. N. (2000). The role of quorum sensing in the in vivo virulence of Pseudomonas aeruginosa. Microbes Infect 2, 1721-1731.

Saiman, L., Chen, Y., Gabriel, P. S. \& Knirsch, C. (2002). Synergistic activities of macrolide antibiotics against Pseudomonas aeruginosa, Burkholderia cepacia, Stenotrophomonas maltophilia, and Alcaligenes xylosoxidans isolated from patients with cystic fibrosis. Antimicrob Agents Chemother 46, 1105-1107.

Singh, P. K., Schaefer, A. L., Parsek, M. R., Moninger, T. O., Welsh, M. J. \& Greenberg, E. P. (2000). Quorum-sensing signals indicate that cystic fibrosis lungs are infected with bacterial biofilms. Nature 407, 762-764.

Skindersoe, M. E., Alhede, M., Phipps, R., Yang, L., Jensen, P. O., Rasmussen, T. B., Bjarnsholt, T., Tolker-Nielsen, T., Høiby, N. \& Givskov, M. (2008). Effects of antibiotics on quorum sensing in Pseudomonas aeruginosa. Antimicrob Agents Chemother 52, 36483663.

Smith, R. S., Harris, S. G., Phipps, R. \& Iglewski, B. H. (2002). The Pseudomonas aeruginosa quorum-sensing molecule $\mathrm{N}$-(3-oxododecanoyl)homoserine lactone contributes to virulence and induces inflammation in vivo. J Bacteriol 184, 1132-1139.

Sofer, D., Gilboa-Garber, N., Belz, A. \& Garber, N. C. (1999). 'Subinhibitory' erythromycin represses production of Pseudomonas aeruginosa lectins, autoinducer and virulence factors. Chemotherapy 45, 335-341.

Tateda, K., Comte, R., Pechère, J. C., Köhler, T., Yamaguchi, K. \& van Delden, C. (2001). Azithromycin inhibits quorum sensing in Pseudomonas aeruginosa. Antimicrob Agents Chemother 45, 19301933.

Tsai, W. C., Rodriguez, M. L., Young, K. S., Deng, J. C., Thannickal, V. J., Tateda, K., Hershenson, M. B. \& Standiford, T. J. (2004). Azithromycin blocks neutrophil recruitment in Pseudomonas endobronchial infection. Am J Respir Crit Care Med 170, 1331-1339.

Van Delden, C. \& Iglewski, B. H. (1998). Cell-to-cell signaling and Pseudomonas aeruginosa infections. Emerg Infect Dis 4, 551-560.

Venturi, V. (2006). Regulation of quorum sensing in Pseudomonas. FEMS Microbiol Rev 30, 274-291.

Wagner, V. E., Li, L.-L., Isabella, V. M. \& Iglewski, B. H. (2007). Analysis of the hierarchy of quorum-sensing regulation in Pseudomonas aeruginosa. Anal Bioanal Chem 387, 469-479.

Willcox, M. D. P., Zhu, H., Conibear, T. C. R., Hume, E. B. H., Givskov, M., Kjelleberg, S. \& Rice, S. A. (2008). Role of quorum sensing by Pseudomonas aeruginosa in microbial keratitis and cystic fibrosis. Microbiology 154, 2184-2194.

Wolter, J. M. \& McCormack, J. G. (1998). The effect of subinhibitory concentrations of antibiotics on adherence of Pseudomonas aeruginosa to cystic fibrosis (CF) and non-CF-affected tracheal epithelial cells. J Infect 37, 217-223. 